\title{
Tensões nas representações sobre a democracia nos atos contra e pró-impeachment do Governo Dilma Rousseff na cobertura do jornal Folha de São Paulo em 2015
}

\section{Valdir José Morigi}

Doutor; Universidade Federal do Rio Grande do Sul, Porto Alegre, RS, Brasil valdir.morigi@gmail.com

\section{Ketlen Stueber}

Mestra; Universidade Federal do Rio Grande do Sul, Porto Alegre, RS, Brasil ketistueber@hotmail.com

\section{Solange Inês Engelmann}

Doutora; Universidade Federal do Rio Grande do Sul; Porto Alegre, RS, Brasil solengel03@gmail.com

\section{Candice Cresqui}

Mestra; Pontifícia Universidade Católica do Rio Grande do Sul; Porto Alegre, RS, Brasil candicecresqui@gmail.com

\section{Resumo}

O artigo aborda as tensões sobre a democracia na cobertura das principais matérias do jornal Folha de São Paulo (versão online), durante os atos contra e a favor do impeachment do Governo Dilma Rousseff (Partido dos Trabalhadores) nos meses de março, agosto e dezembro de 2015. Analisa-se como o jornal constrói e coloca em circulação representações sobre a democracia, a partir das tensões presentes nos atos contra e pró-impeachment. Para tanto, apoiamo-nos sobre a Teoria das Representações Sociais, apresentamos elementos sobre o contexto da ditadura militar no Brasil e características da democracia representativa. Pesquisa de abordagem qualitativa, com base na Análise de Conteúdo e no estudo de ambiências. Conclui-se que as representações e tensões em torno dos valores democráticos visibilizados na cobertura das matérias denunciaram a tentativa de golpe à democracia e chamaram atenção para os problemas que um regime conservador/autoritário impõe à sociedade. No entanto, 
Tensões nas representações sobre a democracia nos atos contra e pró-impeachment do Governo Dilma Rousseff na cobertura do jornal

destacaram-se os enunciados que contribuíram com a disseminação do ódio à democracia, manutenção das condições de desigualdades sociais, negação dos problemas sociais e dos processos de luta por igualdade de direitos e cidadania. Os discursos, eventos e ações que antecederam ao golpe demarcam a dissolução da delicada manutenção do sistema democrático brasileiro.

\section{Palavras-chave}

Representações sociais. Democracia. Tensões contra e próimpeachment. Governo Dilma Rousseff.

\section{Introdução}

Desde 2013, as manifestações populares voltaram a figurar na agenda política do país. Em 2015, essas manifestações adquiriram um caráter de ataque e de defesa do Governo Dilma Rousseff do Partido dos Trabalhadores (PT). A corrupção foi o principal argumento dos grupos contrários ao Governo para justificar o pedido de impeachment da presidenta. Por outro lado, os movimentos em defesa da continuidade do Governo e da manutenção da democracia acusaram os grupos pró-impeachment de "golpistas", uma vez que não se apresentou a comprovação de crime de responsabilidade inquestionável, e alertaram para o enfraquecimento do Estado Democrático de Direito, inclusive pelo próprio judiciário.

A grande mídia brasileira tem atuado como protagonista nesse cenário. A imparcialidade parece não figurar mais entre os pressupostos da reportagem jornalística, ao invés de esclarecer aos cidadãos sobre os acontecimentos, a mídia divulga informações descontextualizadas que confundem a população e restringem a consolidação da democracia brasileira. Diante deste cenário, em agosto de 2016, a Presidenta Dilma Rousseff foi afastada definitivamente do cargo, após a aprovação do seu impeachment pela Câmara dos Deputados e Senado Federal.

De acordo com Ruffato (2016), Singer et al. (2016), Albuquerque e Meneses (2017), compreendemos que o processo de impeachment da Presidenta se trata de um golpe contra a democracia brasileira. Orquestrado pelo Congresso Nacional, em consórcio com o judiciário e com o apoio da imprensa, rupturas que visam retirar direitos conquistados foram efetuadas no processo democrático a fim de barrar as políticas sociais e aprofundar o projeto neoliberal no país. Ruffato (2016) defende que o impeachment de Dilma se configura em um golpe de Estado, devido à ausência de provas de que a presidenta teria cometido 
crime de responsabilidade para seu afastamento ${ }^{1}$, como determina o artigo 9o, da Lei $\mathrm{n}$. 1.079 (BRASIL, 1950). Para ele, a presidenta foi deposta devido à perda de popularidade no Congresso, por promover "faxinas" em órgãos públicos, afastando políticos envolvidos em corrupção e por não impedir investigações da operação Lava-Jato contra políticos.

No artigo o termo impeachment é empregado por se tratar de acontecimentos que antecederam ao golpe e por ser o termo adotado pelo veículo de comunicação do objeto de estudo. Diante de tal fato, interessa-nos saber, como o jornal Folha de São Paulo apresenta a cobertura dos atos contra e a favor do governo Dilma no ano de 2015? A partir desta questão, buscamos compreender quais representações sobre a democracia são estabelecidas e reproduzidas, seja de modo implícito ou explícito. O estudo das representações sobre a democracia a partir das construções simbólicas e tensões na cobertura midiática em relação a este período, justifica-se, pois, “[...] reserva-se aos meios de comunicação de massa um papel destacado na compreensão dos processos de formação e circulação das representações sociais nas sociedades contemporâneas" (SÁ, 1998, p. 43).

O objetivo deste estudo é verificar quais tensões estão presentes na cobertura das principais matérias da versão online do jornal Folha de São Paulo, durante os atos contra e a favor do impeachment do Governo Dilma Rousseff nos meses de março, agosto e dezembro de 2015. 0 viés epistemológico constitui-se a partir da Teoria das Representações Sociais de Moscovici (2012), por considerar os meios de comunicação um dos principais elementos de produção simbólica e representativa na formação de consensos sociais. 0 viés metodológico parte de uma abordagem qualitativa, apoiada nas técnicas de Análise de Conteúdo (AC) de Bardin (2009) e no estudo de ambiências/tensões (MARKOVÁ, 2006), enquanto elementos constitutivos das representações sociais.

\section{As representações sociais, os meios de produção simbólica e as tensões na esfera pública}

A construção de uma esfera pública nas sociedades democráticas necessita do estabelecimento de um conjunto de interações e debates entre os cidadãos, que se viabiliza por meio de uma comunicação centrada no diálogo argumentativo em torno de temáticas e problemas de interesse público, abarcando visões de mundo e objetivos concorrentes, que são essenciais para auxiliar na mudança de posicionamentos. 0 resultado disso é a formação

\footnotetext{
${ }^{1}$ Segundo o Tribunal de Contas da União, a presidenta Dilma não cometeu nenhum dos crimes previstos em lei (BRASIL, 2015 apud MACIEL, 2015). BRASIL. Tribunal de Contas da União. Relatório e parecer prévio sobre as contas do governo da república: exercício 2014. Brasília: TCU, 2015. Apud Maciel (2015).
} 
Tensões nas representações sobre a democracia nos atos contra e pró-impeachment do Governo Dilma Rousseff na cobertura do jornal

de uma sociedade com diversidade de opiniões e visões de mundo equitativas em relação às diferenças sociais, políticas, culturais, etc.

Nesse sentido, Jovchelovitch (2000, p. 175) salienta que "as representações sociais são formas de mediação simbólica firmemente radicadas na esfera pública", a qual se torna o espaço da realidade objetiva e intersubjetiva. É neste terreno que as representações "são geradas, se cristalizam e se transformam", crescem e tomam forma. Para Moscovici (2012, p. 46), as representações estão diretamente ligadas à comunicação, pois estabelecem-se na construção de sentidos e saberes, são uma maneira específica de compreender e comunicar. O objetivo das representações é "[...] abstrair sentido do mundo e introduzir nele ordem e percepções, que reproduzam o mundo de uma forma significativa." Segundo o autor, as representações sempre possuem uma face icônica e outra simbólica interdependentes. E deste modo entende-se que, “[...] representação = imagem/significação; em outras palavras, a representação iguala toda a imagem a uma ideia e toda ideia a uma imagem" (MOSCOVICI, 2012, p. 46). Neste contexto, a comunicação se estabelece por meio de vínculos entre os indivíduos, comunidades e grupos sociais resultando na criação de representações de si, dos outros e de distintas realidades sobre elementos concretos e abstratos que circundam a sociedade em diferentes épocas.

A interação das representações sociais se dá através dos processos de ancoragem e objetivação (ou objetificação). A ancoragem é o processo responsável por recriar permanentemente interpretações e juízos de valor ao classificar (comparar) e nominar (rotular, agregar identidade) aos objetos e, desta forma, contribuir para a objetivação dos mesmos. Conforme Moscovici (2012), “[...] objetivar é descobrir a qualidade icônica de uma ideia, ou ser impreciso; é reproduzir um conceito em uma imagem." (p. 71-72). Deste modo, o autor afirma que as construções da ilusão e da realidade são processadas da mesma maneira, pois primeiramente as pessoas apreendem a imagem e depois o conceito como realidade. Neste processo, muitas variáveis estão implícitas: a cultura, as crenças, a lógica (enquanto forma de assimilação), o uso da linguagem e a memória (enquanto fenômeno sócio histórico).

A ancoragem “[...] mantém a memória em movimento e a memória é dirigida para dentro, está sempre colocando e tirando objetos, pessoas e acontecimentos, que ela classifica de acordo com um tipo e as rotula com um nome" (MOSCOVICI, 2012, p. 78). A objetivação transcende, pois é dirigida para fora, para os outros e “[...] tira daí conceitos e imagens para juntá-los e reproduzi-los no mundo exterior, para fazer as coisas conhecidas a 
Tensões nas representações sobre a democracia nos atos contra e pró-impeachment do Governo Dilma Rousseff na cobertura do jornal

partir do que já é conhecido" (MOSCOVICI, 2012, p. 78). Nesse processo, os meios de comunicação ao divulgarem as informações na esfera pública adquirem um papel central, pois ao mediarem os acontecimentos do passado não os fazem com total isenção e imparcialidade.

Jovchelovitch (2000) aponta que os meios de comunicação são parte do funcionamento da vida social e integram as instituições que influenciam na vivência e na representação da mesma em sociedade. Modificam, assim, as formas de interação, o acesso, o consumo de bens simbólicos e a estrutura da política institucional, alterando as fronteiras entre a esfera pública e privada.

O surgimento da imprensa interfere na criação de uma esfera pública que impõe novas formas de controle às práticas políticas, mediante a publicidade dos governos, que torna mais visível ao público o exercício do poder, amplia a exposição sobre as condutas e as ações dos líderes políticos. Nesse sentido, Jovchelovitch (2000, p. 91) alerta que a imprensa produz significados e valores hegemônicos, assumindo o papel de "ator chave" do poder. Em tal cenário, ao apoiar abertamente algumas políticas e excluir outras, a grande imprensa, consequentemente, impõe e reforça um conjunto de desigualdades e assimetrias em relação às definições sobre a vida pública.

As representações estão compostas também de tensões. Marková (2006) desenvolve um estudo sobre como o pensamento em antinomias torna-se fundamental para a aquisição de conhecimentos. A autora afirma que a lei aristotélica da não contradição "[...] não só fundamentou o conceito de racionalidade, da lógica, da ciência e filosofia na Grécia Antiga, mas forneceu também orientação a todos os sistemas de conhecimento" (MARKOVÁ, 2006, p. 66). A partir de então, a ciência grega tornou-se exata, um sistema fechado e dedutivo que influenciou diversos pensadores como Descartes e seu pensamento positivista que ainda hoje se faz presente em algumas formas de desenvolver conhecimento.

No entanto, Marková (2006) aponta que a lógica da mudança, proposta por Hegel, busca entender as forças interdependentes contidas em um sistema e como os componentes opostos encontravam-se simultaneamente estabelecidos para formar as partes de um todo. As dialéticas de Hegel são sistemas muito bem desenvolvidos da racionalidade, da realidade, da história e do pensamento. Na concepção da autora, o conteúdo e o significado do pensamento são construídos nas representações sociais. As antinomias são compostas por elementos periféricos reunidos que servem de interface para os elementos constitutivos de uma situação concreta. “Os elementos periféricos mantêm a representação dinâmica e, ao 
Tensões nas representações sobre a democracia nos atos contra e pró-impeachment do Governo Dilma Rousseff na cobertura do jornal

mesmo tempo, servem como um sistema regulador, resistindo a grandes mudanças nas representações" (MARKOVÁ, 2006, p. 246). Diante disso, as culturas são perpassadas por vários tipos de antinomias e polarizações, que mediante a ação comunicativa dos cidadãos e da mídia na esfera pública geram um conjunto de tensões, que auxiliam na constituição e propagação das representações sociais.

\section{As representações sobre democracia no contexto brasileiro}

0 conceito de democracia como objeto de estudo e de práxis política assume um caráter complexo, pois, mesmo diante de críticas e limitações, não surgiu outro modelo que melhor se adapte às diferentes demandas e necessidades sociais. Bobbio (2000, p. 30) aponta como definição mínima de democracia um conjunto de regras e procedimentos legais responsáveis por definir "[...] quem está autorizado a tomar as decisões coletivas e com quais procedimentos". Assim, um sistema democrático funciona mediante o estabelecimento de regras e normas responsáveis pela definição de quais indivíduos adquirem autorização para desempenhar o papel de representantes de uma maioria social e tomar as decisões coletivas.

O funcionamento de um governo democrático se efetiva com base na alternância de grupos no poder, mediante eleições livres através do voto, para a escolha dos representantes de uma maioria social. Conforme Kinzo (2004), o processo democrático se viabiliza com a consolidação de partidos políticos sólidos e eleições livres, e fundamenta-se no respeito às instituições, entre as quais os partidos políticos atuam como sujeitos autorizados no intercâmbio entre os indivíduos, representados e o governo (BOBBIO, 2000). 0 processo eleitoral se torna o elemento central que garante as regras do jogo nos governos representativos.

Refletir sobre as diferentes tensões e representações geradas pelos meios de comunicação e suas construções simbólicas significa rememorar o período da ditadura no Brasil e a abertura democrática. O início da década de 1960 foi marcado por uma fase turbulenta na política nacional. Jânio Quadros assumia a Presidência da República e sete meses depois renunciava.

Embora a Constituição garantisse que na renúncia ou impedimento do presidente o cargo seria assumido pelo seu vice, com a saída de Jânio ganha força um movimento militar contra a posse do vice-presidente João Goulart. A polêmica dividiu o país. Os mais conservadores alegavam que Goulart traria instabilidade às instituições e à ordem. Os 
defensores da legalidade, por sua vez, iniciaram um movimento nacional insuflando a população a não permitir o descumprimento da Constituição.

Ao assumir a Presidência, João Goulart dava início a um governo comprometido com os movimentos sociais. Eleito pelos meios sindicais, pelas esquerdas e pelos nacionalistas, Jango tomou posse sob o parlamentarismo até 1963, quando um plebiscito restaurou o presidencialismo. Neste cenário, os movimentos sociais se fortaleciam. Baseado em um programa de reformas socioeconômicas, com as chamadas Reformas de Base, Jango pretendia mexer em áreas importantes do país; como a tributária, a urbana, a cambial, a universitária, e, certamente, a mais polêmica, a agrária, reformando-as. Essas propostas sensibilizaram a nação, mas irritaram as elites agrárias, que tentaram impedir a sua aprovação no Congresso.

Cumprindo o papel de porta-voz das elites, a mídia distorcia e supervalorizava a manifestação popular. As informações que chegavam ao público eram as de ação de subversivos e revolucionários, concluindo pela iminência de uma guerra camponesa no nordeste desempenhada pelas Ligas Camponesas. Desencadeou-se uma campanha alarmista que tachava o governo de demagógico, ditatorial, sindicalista e comunista. Empresários, banqueiros e militares sentiam-se ameaçados pelo espaço que trabalhadores, estudantes e organizações sociais conquistavam no país (CHIAVENATO, 1994).

Porém, para Chiavenato (1994), as Reformas de Base estavam longe de implantar o comunismo no país. Pretendiam agilizar o capitalismo brasileiro, proporcionando-lhe condições de desenvolvimento, com maior participação do povo. Com medo de que Goulart promovesse um golpe de esquerda, os militares, apoiados pelos partidos de oposição (conservadores), e também pelo governo norte-americano, através da CIA (Central Intelligence Agency, Agência Central de Inteligência dos Estados Unidos da América), articularam-se para deter o presidente. E em 31 de março de 1964, os militares tomaram o poder e concretizaram um golpe militar no país, chamado por eles de revolução.

Pode-se dizer que o golpe representou um movimento contra a nascente democracia política brasileira, as reformas sociais e econômicas, a valorização das organizações dos trabalhadores. A verdadeira e dura face do novo regime se revelou imediatamente e as décadas que se seguiram foram marcadas pela perda das liberdades individuais e políticas, censura, perseguições, assassinatos e torturas.

A retomada do sistema democrático brasileiro somente foi conquistada após anos de lutas e contestação contra o regime, promovendo uma abertura democrática a partir de 
1985. Após esse período, realiza-se a inclusão de uma maioria social a partir do sufrágio universal e a ampliação do eleitorado urbano, que contribui para a diminuição do coronelismo eleitoral nas zonas rurais. E a livre concorrência eleitoral entre os diversos partidos políticos, acabando com a alternância dos governos militares no poder (KINZO, 2004).

Outros avanços importantes ocorrem com o reestabelecimento do respeito à liberdade no exercício das organizações políticas, o fortalecimento de sindicatos e movimentos sociais, além da inclusão de partidos de esquerda no sistema político eleitoral. Nesses termos, a viabilidade e o funcionamento do processo democrático necessita de condições igualitárias, para a livre escolha de alternativas entre os indivíduos a serem eleitos, através da liberdade de expressão e opinião dos representados. A garantia desses direitos requer mobilização coletiva e pressão dos representados em relação aos governos (MANIN, 1995).

Rancière (2014) chama atenção para o desenvolvimento de visões de ódio à democracia na sociedade contemporânea, que procuram desqualificar os governos democráticos. Nesses termos, a democracia é considerada uma ameaça à própria sociedade por questionar os privilégios das oligarquias e das elites no poder. Desse modo, a democracia representativa torna-se um sistema fundamental para a maioria social na busca por direitos. "Ela é a potência que, hoje [...] deve lutar contra a confusão desses poderes em uma única e mesma lei da dominação" (RANCIÈRE, 2014, p. 121). A disseminação do ódio contra a democracia procura criar condições para a manutenção de um conjunto de desigualdades entre a população mais pobre, além de tentar negar a dominação das oligarquias econômicas e políticas.

A democracia brasileira parece ainda mais frágil. E o passado histórico ditatorial do país, mesmo recente, não figura como memória para grande parte da população. A transição negociada passou pela negação ou relativização dos crimes cometidos pela ditadura em nome da segurança nacional. De acordo com Padrós (2014), isso impôs no país uma política de silêncio e esquecimento sobre esse período. O Brasil é “[...] paradigmático do esquecimento induzido e da desmemoria oficial" (PADRÓS, 2014, p. 194). Somente nos últimos anos com a instalação da Comissão Nacional da Verdade, e suas instâncias estaduais, o país começara a passar sua trajetória a limpo. A revisão da Lei de Anistia, reivindicada pelos movimentos de resgate histórico, no entanto, ainda é tratada como revanchismo por setores mais conservadores. 


\section{Tensões nas representações sobre a democracia na cobertura contra e pró-impeachment do governo Dilma Rousseff no jornal Folha de S. Paulo}

As representações sociais e suas tensões se encontram inseridas em um contexto social, resultado de memórias e integrado a um período histórico específico. Neste caso, as representações sociais se integram ao contexto contemporâneo, permeadas por tensões relativas aos sentidos e significados acerca do sistema democrático brasileiro; geradas e reforçadas pelos grandes meios de comunicação. Essas tensões se desenvolvem após mais de 50 anos de um período de ditadura militar.

Num contexto de pré-golpe contra a democracia brasileira, houve nas ruas manifestações populares contra e a favor do Governo, reunindo grupos populares e progressistas que defenderam a manutenção de Dilma na presidência e denunciaram o ataque à democracia e aos direitos sociais. E de grupos conservadores contra a corrupção, por meio de um viés moral, que estimulou posturas de ódio contra a democracia e de condenação da política. Parte desses manifestantes defendem o retorno de um regime militar no país.

Diante do papel dos grandes meios de comunicação na visibilidade desta pauta e na convocação das manifestações pelo impeachment e contra o Governo, percebeu-se a instalação de uma instabilidade política e social, que promoveu tensões em torno das representações sobre a democracia e a soberania do voto no país. Assim, considerando o reconhecimento da ação comunicativa como unidade central da análise, também é importante para interligar o conhecimento a um contexto social, o jornal Folha de São Paulo, é o meio efetivo de produções simbólicas para refletirmos acerca da democracia no Brasil, neste estudo.

O jornal Folha de S. Paulo, constituído em 1960, descende da fusão de três jornais do grupo Folha: Folha da Noite (fundado em 1921), Folha da Manhã (1925) e Folha da Tarde (1949). Em 1962, a empresa passava por problemas econômicos, por isso, havia a necessidade de ser administrada a partir de preceitos capitalistas para modernizar jornal. Segundo Dias (2014), a história da Folha de S. Paulo antes do período de democratização do país é demarcada por três períodos: reorganização política, financeira e tecnológica (de 1962 a 1967); busca pelo desenvolvimento de uma "revolução" tecnológica (1964 a 1968); e definição de um projeto político cultural (1974 a 1981).

Além das questões financeiras e a necessidade de manter-se com incentivo de capital externo para se estabilizar, Dias $(2014$, p. 65) relata que "ideologicamente, também não 
havia muita discordância entre o empresariado e o governo militar que tomou posse em 1964. Não foi apenas a Folha, mas praticamente toda a grande imprensa no país apoiou o regime". Os momentos iniciais de consolidação da Folha estão permeados de paradoxos entre questões econômicas e políticas.

A partir de 1970, a censura prévia é suspensa pelo Presidente Geisel. Com as dívidas sanadas e uma maior independência financeira, a Folha busca definir mais claramente seu projeto político-editorial e numa postura de avanços e recuos assume um discurso mais crítico e, ao mesmo tempo, omisso em relação à ditadura. Em 1980, o jornal procura legitimar-se como porta-voz das mobilizações das Diretas-Já devido à necessidade de se ajustar às novas demandas. Assim, a mudança de postura da Folha "[...] se deu a partir de um acordo comum, visando unicamente ampliar sua expansão no mercado e garantir um leitorado que agora clamava por uma orientação" (DIAS, 2014, p. 68).

Em 2011, quando completou 90 anos, a Folha digitalizou e disponibilizou na internet todo seu acervo em um banco de dados desde seu primeiro ano de fundação em 1921. 0 acesso a esta base possibilita verificar como se deu a atuação do jornal nos diferentes períodos históricos do país. De certa forma, buscar as representações sobre a democracia na cobertura da Folha no período recente é uma maneira de verificar como o jornal tem articulado seus vínculos com o passado.

Nesse sentido, o estudo fundamenta-se na Análise de Conteúdo de Bardin (2009). 0 corpus constitui-se nas principais matérias publicadas no portal online do jornal Folha de São Paulo acerca das manifestações pró e contra o impeachment do Governo Dilma (Apêndice A). A análise concentrou-se somente nos textos, e os seus enunciados simbólicos foram categorizados e organizados conforme os quadros 1 e 2 , apresentados abaixo. Ao todo foram analisados seis textos sobre os dois grupos de protestos e interpretados a partir do conceito de ancoragem e objetificação (MOSCOVICI, 2012) e tensões (MARKOVÁ, 2006).

0 primeiro aspecto que deve ser considerado é o papel dos sujeitos na constituição das representações sociais na cobertura da Folha de São Paulo (quadro 1). Pois, as interações entre os sujeitos e a forma com que as ações comunicativas são produzidas e compartilhadas na sociedade são fatores determinantes para a compreensão dos tipos de representação e conhecimento criados e vivenciados na esfera pública. 
Tensões nas representações sobre a democracia nos atos contra e pró-impeachment do Governo Dilma Rousseff na cobertura do jornal

Quadro 1 - Sujeitos citados pela Folha de São Paulo como envolvidos nos atos contra e próimpeachment do Governo Dilma (março, agosto e dezembro de 2015)

\begin{tabular}{|c|c|}
\hline \multicolumn{2}{|c|}{ Sujeitos envolvidos } \\
\hline Contra-impeachment & Pró-impeachment \\
\hline \multicolumn{2}{|c|}{ Organizações } \\
\hline $\begin{array}{l}\text { CUT (Central Única dos Trabalhadores), UNE (União } \\
\text { Nacional dos Estudantes), CTB (Central dos } \\
\text { Trabalhadores e Trabalhadoras do Brasil), MST } \\
\text { (Movimento dos Trabalhadores Rurais Sem Terra) } \\
\text { MTST (Movimento dos Trabalhadores Sem Teto), } \\
\text { PSOL (Partido Socialismo e Liberdade), PT (Partido } \\
\text { dos Trabalhadores), Intersindical, Central de } \\
\text { Movimentos Sociais (CMS), Frente Povo Sem Medo. }\end{array}$ & $\begin{array}{l}\text { MBL (Movimento Brasil Livre), Vem Pra } \\
\text { Rua, Revoltados Online, SOS Forças } \\
\text { Armadas, SD (Partido Solidariedade), PMDB } \\
\text { (Partido do Movimento Democrático do } \\
\text { Brasil) e PSDB (Partido da Social } \\
\text { Democracia Brasileira). }\end{array}$ \\
\hline \multicolumn{2}{|l|}{ Fontes } \\
\hline $\begin{array}{l}\text { Presidente nacional CUT, Vagner Freitas; Dirigente do } \\
\text { MST, Antônia Ivonei de Melo Silva; Presidente } \\
\text { CUT/Goiânia, Bia de Lima; Presidente da CTB, Sinval } \\
\text { Costa; Vice-presidente Michel Temer (PMDB); Líder do } \\
\text { MST, Gilmar Mauro; Coordenador-geral da Central de } \\
\text { Movimentos Sociais, Raimundo Bonfim; Coordenador } \\
\text { do MTST, Guilherme Boulos; Ministro de Direitos } \\
\text { Humanos, Paulo Vannuchi; Presidente estadual do PT, } \\
\text { Emídio de Souza; Ministro de Comunicação Social do } \\
\text { Governo Dilma, Edinho Silva. }\end{array}$ & $\begin{array}{l}\text { Deputado federal, Paulinho (SD-SP); } \\
\text { Deputado federal, Floriano Pesaro (PSDB); } \\
\text { Senador, Aécio Neves (PSDB); ex-candidato } \\
\text { à presidência, Eduardo Jorge (PV); Senador, } \\
\text { Aloysio Nunes Ferreira (PSDB-SP); Senador, } \\
\text { José Serra (PSDB); além de fontes não } \\
\text { identificadas: "Um assessor"... }\end{array}$ \\
\hline
\end{tabular}

Fonte: Elaborado pelos autores.

No quadro acima, observa-se que a cobertura do jornal Folha de S. Paulo apresenta um número maior de organizações que convocam e participam dos atos contra o impeachment do Governo Dilma. Os agentes responsáveis pelos atos a favor do mandato são compostos, principalmente, por movimentos sociais e centrais sindicais, consolidados no país desde o processo de abertura democrática e que têm como principais bandeiras a defesa de diretos trabalhistas, humanos, sociais e de acesso democrático à terra e à moradia.

Nos atos pró-impeachment, por outro lado, há um número menor de entidades convocando e participando, entre eles estão movimentos recentes e pouco conhecidos pela maioria da população, que surgem a partir das primeiras mobilizações pelo impeachment de Dilma, em novembro de 2014. Como, por exemplo, o MBL (Movimento Brasil Livre), que possui como pauta central a realização do impeachment e expressa basicamente anseios da classe média e alta, ou por movimentos extremistas e de pouca expressão, mas que já 
Tensões nas representações sobre a democracia nos atos contra e pró-impeachment do Governo Dilma Rousseff na cobertura do jornal

estiveram presentes em outros momentos históricos, como o SOS Forças Armadas, que defendem uma nova "intervenção militar" no país.

Outra questão que chama atenção na cobertura são as fontes acionadas para realização das coberturas da Folha. Enquanto nos atos contra o impeachment há um número significativamente maior de fontes ouvidas que falam sobre as pautas dos protestos (em sua maioria, representantes de entidades envolvidas nos atos), demonstrando o protagonismo dessas organizações nas mobilizações; nos atos pró-impeachment do governo as principais fontes se restringem aos políticos da oposição, que aparecem pautando as razões dos protestos. Ao todo, foram ouvidas treze fontes nas matérias referentes aos movimentos contra o impeachment, enquanto naqueles referentes aos atos pró-impeachment foram ouvidas somente seis fontes identificadas.

Na cobertura de dezembro, o jornal também usa como fonte "um assessor", não o identificando. Neste caso, o protagonismo dos atos é transferido aos partidos de oposição ao governo e a fontes desconhecidas. Essa abordagem de fontes leva a questionamentos quanto a própria legitimidade desses movimentos e seus representantes. Porque a Folha não ouve, nas principais matérias, os membros dos movimentos que convocam as mobilizações pelo impeachment? Estariam estes movimentos emergentes apenas sendo utilizados como massa de manobra pelos partidos de direita na intenção de destituir o Governo Dilma, com o argumento da corrupção? As principais ancoragens das representações a partir da teoria de Moscovici (2012) são fundamentais na construção de sentidos. Assim, evidenciam os discursos sobre a democracia presentes na cobertura das manifestações contra e próimpeachment.

Nos grupos contra o impeachment de Dilma percebe-se que os discursos se encontram ancorados na concepção de que o afastamento da presidente, sem crime de responsabilidade, representaria uma ameaça ao processo democrático e prejudicaria a soberania do voto popular. Com essa ancoragem, os movimentos objetivaram seus discursos na defesa do modelo neo-desenvolvimentista e de melhorarias sociais, adotadas em parte pelos governos do PT, como o combate à privatização e a defesa das empresas públicas, como a Petrobras. Porém, não deixaram de criticar as medidas de ajuste fiscal e de austeridade adotadas pelo Governo Dilma, que prejudicaram os trabalhadores. Essas manifestações revelaram uma postura crítica desses segmentos na cobrança de reformas, como a reforma política e agrária, sendo ancoradas, de forma geral, no discurso de que o processo do impeachment representaria uma tentativa de golpe, por parte da direita e da 
elite, com objetivo de promover o desmonte de políticas públicas e direitos, ameaçando a democracia do país. Em geral, os argumentos utilizados pelas fontes ouvidas evidenciam que o impeachment é ilegítimo, por se tratar de chantagem do presidente da Câmara dos Deputados, Eduardo Cunha, e representar uma saída "à direita” para as crises econômicas e política no país. Percebe-se nos discursos a esperança de que as manifestações pudessem impedir a consumação do impeachment da presidenta.

Nos protestos pró-impeachment, as representações se apresentam de formas difusas e controversas. Quanto à falta de espaço encontrada nessas manifestações para os discursos de lideranças políticas (caso de representantes do PSDB em uma das manifestações), estes argumentaram que o Governo Dilma desmoralizou a classe política, devido às denúncias de corrupção de membros de seu governo. Em geral, as narrativas pró-impedimento se ancoram na ideia de que a rejeição à presidenta cresceu devido à crise econômica e que a saída para o país seria o governo aceitar a agenda de reformas apresentada pelo Partido do Movimento Democrático Brasileiro (PMDB), intitulada "Ponte para o Futuro" e apoiada por partidos de direita e centro, de oposição ao governo. Também valoravam os protestos por acontecerem sem a direção de partidos ou sindicados, buscando imprimir a ideia de que estes ocorriam de forma "espontânea" e pacífica. Porém, reforça-se a convocação de Aécio Neves do Partido da Social Democracia Brasileira (PSDB), candidato à presidência derrotado por Dilma, para que a população se mantenha nas ruas participando das manifestações pelo impeachment.

A partir destes argumentos, buscaram deslegitimar e esvaziar a atuação de instituições históricas de representação de classe dos trabalhadores como os sindicatos, movimentos sociais, e de partidos de esquerda, bem como vincular os mesmos à defesa do mandato de Dilma, sem qualquer reflexão crítica. Ao mesmo tempo, uma fonte ouvida se opôs ao impeachment por considerá-lo uma "solução autoritária em relação ao processo democrático". Ainda que controversas, percebe-se que a principal representação que se busca disseminar pelas fontes é de que o impeachment é necessário porque a rejeição ao Governo Dilma aumentou no país devido à crise econômica e que por isso seu governo se encontra desmoralizado. Em nenhum momento cita-se algum crime cometido pela presidenta para justificar seu afastamento definitivo do cargo. Porém, é importante registrar que as fontes ouvidas pelo jornal, nas matérias analisadas, são todas de políticos e de oposição ao governo. 
Tensões nas representações sobre a democracia nos atos contra e pró-impeachment do Governo Dilma Rousseff na cobertura do jornal

Conforme Marková (2006), as tensões podem se manifestar através das diferentes formas e caminhos no entendimento de uma realidade social no qual as distinções fazem parte. As antinomias estão presentes na linguagem e são elementos constitutivos que auxiliam nas distinções entre os acontecimentos sociais e suas representações. Abaixo, foram identificadas algumas tensões nas representações sobre a democracia expressas através das antinomias encontradas na cobertura do jornal Folha de São Paulo. Porém, de forma geral, as tensões polarizadas pela cobertura do jornal apresentam poucos elementos sobre a dimensão da linguagem em torno das representações da democracia e se concentram principalmente na oposição para diferenciar os dois grupos, entre as motivações dos protestos, as cores vestidas pelos manifestantes e no número de participantes.

Quadro 2 - Tensões nas representações sobre a democracia: as antinomias na cobertura da Folha de São Paulo nos atos contra e pró-impeachment do Governo Dilma

\begin{tabular}{|c|c|}
\hline \multicolumn{2}{|c|}{ Antinomias } \\
\hline Contra-impeachment & Pró-impeachment \\
\hline \multicolumn{2}{|c|}{ Motivações dos protestos } \\
\hline $\begin{array}{l}\text { Permanência de Dilma, soberania do voto e pela } \\
\text { democracia. }\end{array}$ & $\begin{array}{c}\text { A favor do impeachment de Dilma e aversão } \\
\text { ao PT. }\end{array}$ \\
\hline Fora Cunha & Fora PT \\
\hline Denúncia de golpe & $\begin{array}{l}\text { Denúncias de corrupção na Petrobrás; } \\
\text { pedidos de intervenção militar }\end{array}$ \\
\hline Crítica ao ajuste fiscal & Crítica seletiva à corrupção \\
\hline Reforma política e reforma agrária & Hostilização aos partidos e políticos \\
\hline \multicolumn{2}{|c|}{ Coloração predominante } \\
\hline $\begin{array}{c}\text { Maioria dos manifestantes vestem roupas } \\
\text { vermelhas }\end{array}$ & $\begin{array}{c}\text { Maioria dos manifestantes vestem roupas } \\
\text { verdes e amarelas }\end{array}$ \\
\hline \multicolumn{2}{|c|}{ Uso de dados quantitativos para descrever a participação popular } \\
\hline Números quebrados e foco na pauta & $\begin{array}{l}\text { Números arredondados (inteiros); uso de } \\
\text { adjetivos de grandeza/proporção e foco na } \\
\text { participação }\end{array}$ \\
\hline
\end{tabular}

Fonte: Elaborado pelos autores.

Na cobertura da Folha sobre os atos, a concepção sobre democracia não aparece de forma explícita, ou seja, não há a definição do conceito em nenhuma das matérias. No decorrer da análise percebem-se alguns aspectos sobre a temática, que surgem de modo implícito e subjetivo. No entanto, é importante considerar que toda a movimentação política que compõe este estudo implica diretamente sobre o conceito de democracia, no campo simbólico e social. 
Assim, o quadro 2 apresenta alguns aspectos que revelam tensões em relação à democracia. Entre eles, as motivações dos protestos: a defesa da permanência de Dilma no Governo versus seu impeachment. Para Bobbio (2000), a democracia depende de um conjunto de regras que garantam processos eleitorais democráticos, através da escolha de representantes autorizados na tomada de decisões coletivas durante o período de cada mandato. A presidenta Dilma foi eleita de forma democrática pela maioria dos votos, garantindo as regras do jogo político (BOBBIO, 2000). Ao mesmo tempo, não ficou provado crime de responsabilidade contra ela para motivar o impeachment (RUFFATO, 2016; CORRÊA, 2015; GALHARDO, 2015). Nesse sentido, a abertura do processo de impeachment da presidenta cria tensões em relação ao respeito das regras democráticas construídas e reafirmadas historicamente no país, desde a redemocratização em 1985. Bem como manifesta visões contrárias entre juristas e alguns políticos em relação à lei sobre o impeachment prevista na Constituição Federal, essencialmente do Congresso Nacional, Câmara dos Deputados e Senado que votaram o processo.

Porém, essas questões relativas às interpretações sobre a lei não aparecem nas matérias analisadas. Abre-se um precedente perigoso em relação ao funcionamento do sistema democrático e a sua continuidade no país. Por um lado se verifica a defesa do sistema democrático brasileiro e por outro a existência de um ataque à permanência e ao seu funcionamento.

Observa-se um conjunto de tensões nas representações sobre o sistema democrático que recaem entre a denúncia do golpe em oposição à denúncia de corrupção e defesa de intervenção militar. Enquanto as entidades do lado contrário ao impeachment denunciam que a sua realização se caracterizaria como golpe de Estado, por outro, o grupo que defende a saída de Dilma, aplica a pauta da corrupção para responsabilizar de forma seletiva um único partido. Os grupos pró-impeachment utilizam-se de julgamentos morais e argumentos descontextualizados acerca das causas do problema da corrupção no Brasil. Uma parte defende a intervenção militar como instrumento de moralização da política e do problema da corrupção do PT, reduzindo toda a problemática em torno dessa questão no país, a um partido e os governos do mesmo.

Outras tensões estão presentes na defesa de reformas como a política e a agrária versus a hostilização de partidos políticos. Os grupos contra o impeachment apresentam como saída à crise política e à corrupção reformas de longo prazo, que busquem tornar o processo eleitoral mais igualitário, combatendo, por exemplo, o financiamento de empresas 
privadas nas campanhas eleitorais, e defendem o combate à concentração de terras com a implantação de um programa de reforma agrária. Por outro lado, a cobertura mostra que os movimentos pró-impeachment apontam como alternativa ao combate da corrupção no Brasil a hostilização e o esvaziamento do instrumento dos partidos políticos e dos movimentos sociais populares.

Ao se fazer o uso de dados quantitativos para descrever a participação popular, a referência ao número de participantes nos atos também evidencia tensões na cobertura da Folha. Nos atos pró-impeachment, os números citados são arredondados (inteiros). Faz-se ainda o uso de adjetivos de grandeza e proporção para destacar a participação social. 0 foco das matérias se concentram no volume de participantes como elemento de destaque dos fatos. Já nas matérias contrárias ao impeachment os números são quebrados e pouco destacados. As matérias demonstram pouca atenção aos números e mais destaque para as pautas. Esse recurso de linguagem nas referências numéricas procura reforçar o pretenso apoio popular ao impeachment.

As antinomias mais explícitas na cobertura da Folha estão no destaque das descrições à respeito das cores das roupas utilizadas pelos manifestantes. As imagens das matérias analisadas procuram dar destaque, nos protestos contra o impeachment, a grupos de pessoas vestidas com cores vermelhas e portando bandeiras do PT, MST, centrais sindicais, bem como placas e faixas de apoio à presidenta e contra seu afastamento, com dizeres: "em defesa da democracia", da "Petrobrás", "reforma política", "contra o golpe”, etc. Nos protestos pelo afastamento de Dilma, os destaques são para pessoas vestindo camisetas da Seleção Brasileira de Futebol e roupas verdes e amarelas, e com bandeiras do Brasil e faixas pedindo "impeachment já", "fora Dilma e PT", "contra corrupção", "intervenção militar", etc.

Observa-se que há uma polarização nítida entre as posições "pró" e "contra". Enquanto as cores da bandeira nacional são associadas aos movimentos pró-impeachment, a cobertura das manifestações contrárias ao impeachment são simbolizadas pela cor vermelha, presente nas bandeiras de alguns partidos políticos e movimentos sociais. Assim, através das cores se evidenciam as tensões nas representações sobre o acontecimento e que nos remetem a outros imaginários marcados historicamente em que os "vermelhos" são associados aos "comunistas" e o "verde e amarelo" representam os "brasileiros cívicos" "defensores da ordem" da "Pátria". 
O destaque nas diferenças, observados através das cores e das posturas políticas, reforça a ideia dos conflitos e suas antinomias como polos opostos irreconciliáveis. Em uma sociedade plural e democrática todos têm direito a se manifestarem. A diversidade cultural e a pluralidade de cores, opiniões, credos, sexos, entre outros é parte do respeito às diferenças e do processo democrático. Nesse sentido, ao colocar em circulação as representações sobre os protestos pela manutenção e o afastamento de Dilma, a Folha evidencia sua posição política, colaborando para enfraquecer a democracia e os processos de luta que promoveram o reconhecimento de direitos e inclusão de minorias sociais no Brasil.

\section{Considerações finais}

A partir do debate dos autores e da identificação das tensões nas representações sobre a democracia através das antinomias na cobertura da Folha de S. Paulo, percebe-se a importância no aprofundamento da democracia para além da participação dos cidadãos no processo eleitoral. No caso brasileiro, também é preciso resolver os problemas da contestação pública e da participação dos cidadãos, através de políticas públicas que erradiquem a pobreza extrema e as desigualdades sociais, ampliando o espaço de participação política dos cidadãos.

Conforme Rancière (2014), o julgamento moralizante da política estimula o ódio contra a democracia e procura desqualificar esse sistema que deveria ser utilizado pela sociedade como instrumento de questionamento contra as desigualdades e luta pelo acesso de direitos. 0 ódio à democracia transforma o sistema democrático em operador ideológico, despolitiza as questões da vida pública, reduzindo-as a simples fenômenos sociais. Nega-se com isso, os mecanismos de dominação estruturais presentes na sociedade e o domínio das oligarquias é mascarado, o que, consequentemente, gera um aprofundamento das desigualdades sociais.

A partir de Moscovici (2012), Jovchelovitch (2000) e Marková (2006) torna-se evidente que ao atuar como agente de produção simbólica, a mídia perpetua representações sociais presentes na sociedade, ao mesmo tempo em que constrói e coloca em circulação novas formas de representações. Esse papel é evidente nas narrativas construídas pela Folha sobre os atos contra e pró-impeachment. Nas coberturas do jornal, há um grupo que denuncia a tentativa de golpe à democracia e chama atenção para os problemas que um regime conservador/autoritário impõe a sociedade. E outro grupo que transforma o sistema democrático em operador ideológico, em que a democracia passa a ser vista como uma 
Tensões nas representações sobre a democracia nos atos contra e pró-impeachment do Governo Dilma Rousseff na cobertura do jornal

ameaça. Ao mesmo tempo em que evoca, com uma justificativa moralizante de "acabar com a corrupção", soluções extremas de conservadorismo, como pedidos de intervenção militar (por parte de alguns grupos mais radicais) invertem as principais características de um Estado Democrático.

Por meio das tensões nas representações sobre a democracia na cobertura das matérias da Folha, observou-se uma clara ameaça à manutenção do sistema democrático brasileiro, que se consolida somente a partir de 1985, após mais de 20 anos de dura repressão do regime civil-militar. Percebe-se ainda a necessidade de combater os discursos e a disseminação do ódio à democracia que procuram manter as desigualdades sociais, mascarar os problemas sociais e barrar processos de lutas populares por igualdade, justiça de direitos e cidadania.

\section{Referências}

ALBUQUERQUE; Newton de Menezes; MENESES, Ecila Moreira de. 0 golpe no Brasil como construção da "democracia" da subcidadania. Polis: revista latinoamericana, Santiago, v. 16, n. 46 , abr. 2017.

BARDIN, Laurence. Análise de conteúdo. Lisboa: Edições 70, 2009.

BRASIL. Lei no 1.079. Brasília: 10 de abril de 1950. Disponível em: <www.planalto.gov.br/ccivil_03/leis/L1079.htm>. Acesso em: 26 jul. 2017.

BOBBIO, Norberto. 0 futuro da democracia: uma defesa das regras do jogo. 11. ed. Rio de Janeiro: Paz e Terra, 2000.

CHIAVENATO, Júlio José. 0 golpe de 64 e a ditadura militar. São Paulo: Moderna, 1994.

CORRÊA, Alessandra. 5 razões pelas quais impeachment de Dilma é improvável, segundo brasilianistas. BBC Brasil, [S.l.], 2 mar. 2015.

DIAS, André Bonsanto. 0 presente da memória: usos do passado e as reconstruções de identidade da Folha de S. Paulo entre o "golpe de 1964" e a "ditabranda". Jundiaí: Paco Editorial, 2014.

JOVCHELOVITCH, Sandra. Representações sociais na esfera pública: a construção simbólica dos espaços públicos no Brasil. Petrópolis: Vozes, 2000.

KINZO, Maria D’Alva G. Partidos, eleições e democracia no Brasil pós-1985. Revista Brasileira de Ciências Sociais, São Paulo, v. 19, n. 54, p. 23-41, fev. 2004.

MACIEL, Pedro. Dilma cometeu crime de responsabilidade? Brasil 247, São Paulo, 9 out. 2015. 
MANIN, Bernard. As metamorfoses do governo representativo. Revista Brasileira de Ciências Sociais, São Paulo, v. 10, n. 29. out. 1995.

MARKOVÁ, Ivana. Dialogicidade e representações sociais: as dinâmicas da mente. Petrópolis, RJ: Vozes, 2006.

MOSCOVICI, Serge. Representações Sociais: investigações em psicologia social. 9. ed. Petropolis, RJ: Vozes, 2012.

GALHARDO, Ricardo. Para ex-presidente do Supremo não há motivo para impeachment de Dilma Rousseff. 0 Estado de São Paulo. São Paulo, 21 set. 2015.

PADRÓS, Henrique Serra. A história e a memória confiscadas: o tempo presente e as ditaduras de segurança nacional. In: SIGMUND FREUD Associação Psicanalítica (Org.). Clínicas do testemunho: reparação psíquica e construção de memórias. Porto Alegre: Criação Humana, 2014.

RANCIÈRE, Jacques. 0 ódio à democracia. São Paulo: Boitempo, 2014.

RUFFATO, Luiz. O golpe contra Dilma Rousseff. El País Brasil, [S.l.], 1 set. 2016.

SINGER, André et al. Por que gritamos golpe? Para entender o impeachment e a crise política no Brasil. São Paulo: Boitempo, 2016.

SÁ, Celso Pereira de. A construção do objeto de pesquisa em representações sociais. Rio de Janeiro: Ed. UERJ, 1998.

\section{Apêndice a - Matérias Analisadas}

CRUZ, Valdo. Adesão menor em atos reforça desejo do governo de acelerar tramitação.

Folha de S. Paulo, Brasília, 13 dez. 2016. Disponível em:

<http://www1.folha.uol.com.br/poder/2015/12/1718639-adesao-menor-em-atos-reforcadesejo-do-governo-de-acelerar-tramitacao.shtml>. Acesso em: 25 maio 2017.

FOLHA DE S. PAULO. Ao menos 32 cidades são palcos de atos anti-impeachment. Folha de S. Paulo, São Paulo, 20 ago. 2015. Disponível em: <http://www1.folha.uol.com.br/poder/2015/08/1671568-ao-menos-32-cidades-saopalcos-de-atos-anti-impeachment.shtml>. Acesso em: 15 maio 2017.

FOLHA DE S. PAULO. Ato contra impeachment reúne 55 mil pessoas em SP, segundo Datafolha. Folha de S. Paulo. São Paulo, 16 dez. 2015. Disponível em: <http://www1.folha.uol.com.br/poder/2015/12/1720023-ato-contra-impeachment-reune55-mil-pessoas-em-sp-segundo-datafolha.shtml>. Acesso em: 12 maio 2017.

FOLHA DE S. PAULO. Protestos contra governo Dilma ocorrem em todos os estados e no DF. Folha de S, Paulo, São Paulo, 16 ago. 2015. Disponível em: <http://www1.folha.uol.com.br/poder/2015/08/1669405-protestos-contra-governodilma-ocorrem-em-oito-capitais-e-no-df.shtml>. Acesso em: 21 maio 2017. 
FOLHA DE S. PAULO. Protestos contra o governo reúnem quase 1 milhão pelo país. Folha de S. Paulo, São Paulo, 15 mar. 2015. Disponível em:

<http://www1.folha.uol.com.br/poder/2015/03/1603286-protestos-contra-o-governoreune-quase-1-milhao-pelo-pais.shtml>. Acesso em: 20 maio 2017.

REIS, Lucas. Atos criticam governo, mas defendem Dilma e rebatem impeachment. Folha de S. Paulo, São Paulo, 13 mar. 2015. Disponível em: <http://www1.folha.uol.com.br/poder/2015/03/1602392-atos-criticam-governo-masdefendem-dilma-e-rebatem-impeachment.shtml>. Acesso em: 10 maio 2017.

\title{
Tensions in the representations on \\ democracy in the acts against and pro- impeachment of the Dilma Rousseff administration in the coverage of the newspaper Folha de São Paulo in 2015
}

\begin{abstract}
This article analyzes the tensions about democracy in the coverage of the main articles of the newspaper Folha de São Paulo (online version) during the acts against and proimpeachment of the Dilma Rousseff (PT) administration in March, August and December 2015. It analyses how the newspaper refers and circulates representations about democracy based on the present tensions in demonstrations against and pro-impeachment. Therefore, we rely on the Theory of Social Representations (TSR) and present elements about the context of the military dictatorship in Brazil and the characteristics of representative democracy. It is a qualitative research based on Content Analysis and on the study of ambiences. It is concluded that the representations and tensions surrounding the democratic values seen in the coverage of the articles denounced the attempted coup against democracy and drew attention to the problems that a conservative/ authoritarian regime imposes on society. However, it was highlighted the statements that contributed to the spread of the hatred of democracy, to the maintenance of social inequalities circumstances, to the denial of social problems and processes of struggle for equal rights and citizenship. The speeches, events and actions that preceded the coup demarcate the dissolution of the delicate maintenance of the Brazilian democratic system.
\end{abstract}

\section{Keywords}

Social representations. Democracy. Tensions against and proimpeachment. Dilma Rousseff administration. 